$16^{\text {th }}$ International Conference on

AEROSPACE SCIENCES \& AVIATION TECHNOLOGY,

ASAT - 16 - May 26 - 28, 2015, E-Mail: asat@ mtc.edu.eg

Military Technical College, Kobry Elkobbah, Cairo, Egypt

Tel : +(202) 24025292 - 24036138, Fax: +(202) 22621908

\title{
The Corrosion of Copper Metal in HCl Solutions and the effect of Molybdate and Chromate
}

\author{
A. E.E. Foad El-Sherbini ${ }^{*}$ B. Mostafa M. H. Khalil ${ }^{\dagger}$, C. Eman H. Ismail ${ }^{\ddagger}$ D. Soha S.Tobar ${ }^{\S}$
}

\begin{abstract}
Dissolution characteristics of copper in hydrochloric acid medium and the effect of potassium chromate and sodium molybdate on the corrosion process have been studied using potentiodynamic technique, and Electro impedance spectroscopy (EIS). corrosion current density $\left(I_{\text {corr }}\right)$ were obtained by Tafel extrapolation technique. Charge transfer resistance $\left(R_{\mathrm{ct}}\right)$ was obtained from the electrochemical impedance spectroscopy (EIS). The corrosion rate was retarded in presence of sodium molybdate mainly because of the adsorption of the inhibitor on the electrode surface and it was found that the optimum concentration of this inhibitor in $1 \mathrm{M}$ $\mathrm{HCl}$ was $0.008 \mathrm{M}$ with an protection efficiency $79.17 \%$, while the corrosion rate was accelerated in presence of potassium chromate.
\end{abstract}

\section{Introduction}

Copper has wide applications in industry owing to its high electrical and thermal conductivities, mechanical workability, and its relatively noble properties. It is employed extensively for condensers, evaporators and fractionating columns in the chemical industry [1]. Copper is also exclusively used for piping and delivery of water for marine industry. These pipes are frequently employed in a medium where $\mathrm{Cl}^{-}$ions are present [2]. In some particular environmental conditions, attack by pitting sometimes occurs. These problems result from the presence of specific aggressive species such as chloride, sulfate or nitrate. Each of these species alone can produce pitting corrosion in copper but with different levels of aggressiveness. Sulfate ions appear more aggressive than chloride ions and nitrate ions are more aggressive than sulfate ions. [3, 4] Pitting corrosion is recognized as an insidious type of attack that results in many unexpected failures of metallic structures. The pitting corrosion of metals and alloys occurs when passivity breaks down at local points on the surfaces exposed to corrosive environments containing aggressive anions [5-9], at these points, anodic dissolution proceeds while the major part of surface remains passive.

*Prof. of physical chemistry, Chemistry Department, Faculty of Science, Ain Shams University, 11566, Abbassia, Cairo, Egypt.

$\dagger$ Prof. of inorganic chemistry, Chemistry Department, Faculty of Science, Ain Shams University, 11566, Abbassia, Cairo, Egypt.

\# Assist. Prof. of inorganic chemistry, Chemistry Department, Faculty of Science, Ain Shams University, 11566, Abbassia, Cairo, Egypt \& Chemistry Department, Faculty of Science ,Taibah University, 344, Almadina Almunawarah, KSA.

${ }^{\S}$ Chemist, The Egyptian Chemistry Administration, Ramsis st., Cairo, Egypt \& Chemistry Department, Faculty of Science, Ain Shams University, 11566, Abbassia, Cairo, Egypt. 
It is well-known that corrosion products have a negative effect on heat transfer on the copper based heat exchanger, which can be reduced by periodic cleaning in hydrochloric acid pickling solutions. Corrosion inhibitors could effectively eliminates some of the undesirable reaction connected with destructive effects of hydrochloric acid pickling solutions on copper surface and prevents its dissolution.[10-13]

Copper and copper alloys are materials broadly used in drinking distribution systems. In soft waters with slightly acidic $\mathrm{pH}$ values, the metal can be actively dissolved releasing important quantities

of $\mathrm{Cu}^{2+}$, which can be harmful for the health of the consumers [14]. Corrosion inhibitors have been used to prevent the dissolution of copper. These inhibitors should be innocuous for human consumption and they should not have a negative impact on the environment.

A compound that is frequently employed for this purpose is sodium orthophosphate [15-20]. The action mechanism of this inhibitor is not clearly understood but it was suggested that it reduces the copper solubility forming a cupric phosphate layer on copper [15,21]. However, there is no exhaustive study that evaluates the composition, thickness and other related characteristics of this layer using in situ techniques. When the electrolyte composition and $\mathrm{pH}$ allow the development of a superficial protective layer on the metal, $\mathrm{Cu}^{2+}$ release to the medium is minimum. However, this layer can suffer localized rupture or pitting that can lead to pipe perforation [22].

In this work, The effect of different concentrations of $\mathrm{HCl}(0.5,1.0,1.5,2.0,2.5 \mathrm{M})$, and some inorganic compounds as potassium chromate and sodium molybdate (with $1.0 \mathrm{M} \mathrm{HCl}$ as blank ) were studied on the corrosion performance of $\mathrm{Cu}$.

\section{Experimental:}

The working electrode employed in the present work was made from pure copper rod (99.9 $\%)$ axially embedded in an araldite holder to offer a diameter $(0.8 \mathrm{~cm})$. Prior to each experiment, the working electrode was polished successively with fine grade emery papers. The polished metal surface was rinsed with ethanol and distilled water before dipping it into the electrolytic cell. A platinum wire was used as the counter electrode. Silver/silver chloride $(\mathrm{Ag} / \mathrm{AgCl})$ electrode was used as a reference electrode to which all potentials are referred. For each run, a freshly prepared solution as well as a clean set of electrode was used. Potentiodynamic polarization technique and Electro impedance spectroscopy (EIS) were employed using a potentioscan type apparatus (potetiostat / Gill AC SERIAL No. 948). The experiments of Potentiodynamic polarization technique were carried out by changing the electrode potential automatically from $-100 \mathrm{mV}$ to $500 \mathrm{mV}$ at scan rate $10 \mathrm{mV} / \mathrm{S}$ till the end of the experiment. The experiments of EIS were carried out using AC signals in the frequency range between $30 \mathrm{KHz}$ and $1 \mathrm{~Hz}$. The All solutions were freshly prepared using distilled water and Analar chemicals which were from Merk.

\section{Results and Discussion}

\section{Potentiodynamic polarization measurements:}

\subsection{Effect of different concentrations of $\mathrm{HCl}$ :}

Fig.(1) illustrates the potentiodynamic E- I curves for Copper in different concentrations 0.5$2.5 \mathrm{M} \mathrm{HCl}$ solution at $25^{\circ} \mathrm{C}$. These curves were swept from -1 to $0.5 \mathrm{~V}$ at scan rate $10 \mathrm{mV} / \mathrm{S}$. The curves imply that on positive going sweep the cathodic current corresponding to Hydrogen evolution reaction decreases gradually and changes its sign at zero potential $\mathrm{E}_{\mathrm{i}=0}$. The anodic excrusion exhibits active- passive - transition. The active dissolution involves the appearance of two anodic peaks $\left(\mathrm{P}_{\mathrm{A} 1}, \mathrm{P}_{\mathrm{A} 2}\right)$ followed by a permanent passive region. 
The first anodic peak $\mathrm{PA}_{1}$ located at almost $0.08 \mathrm{~V}$ is due to the formation and adsorption of insoluble $\mathrm{CuCl}_{\text {ads }}$ species on the copper surface, according to the following reactions [23-24]:

$\mathrm{Cu} \rightarrow \mathrm{Cu}^{+}+\mathrm{e}^{-}$

$\mathrm{Cu}^{+}+\mathrm{Cl}^{-} \rightarrow \mathrm{CuCl}_{\mathrm{ads}}$

The insoluble $\mathrm{CuCl}_{\text {ads }}$ species will retarded the dissolution process and the current densities will drop down to a minimum current density the density will increase again forming second oxidation peak $\mathrm{P}_{\mathrm{A} 2}$ located at $0.26 \mathrm{~V}$. Formation of $\mathrm{P}_{\mathrm{A} 2}$ due to oxidation of the cuprous chloride complex to cupric chloride according to the following reactions [25].

$\mathrm{CuCl}_{\mathrm{ads}}+\mathrm{Cl}^{-} \rightarrow \mathrm{CuCl}_{2}$

$\mathrm{CuCl}_{2}^{-} \rightarrow \mathrm{Cu}^{2+} 2 \mathrm{Cl}^{-}+\mathrm{e}^{-}$

Inspection of the curves of figure (1) reveal that the increasing addition of $\mathrm{HCl}$ concentration increase the height of the anodic dissolution density of the peak currents $\mathrm{I}_{\mathrm{PA} 1}$ and $\mathrm{E}_{\text {corr }}$ shifts to more positive values, while the peak current density of I $\mathrm{PA}_{2}$ decrease.

A straight line relation was obtained between the logarithm of $\mathrm{I}_{\mathrm{PA} 1}$ and the logarithm of concentration of $\mathrm{HCl}$ as shown in Fig. (2).

The equation for the straight line is represented by

$\log \mathrm{I}_{\mathrm{A}}=\mathrm{a}+\mathrm{b} \log \mathrm{C}_{\mathrm{HCl}}$

Where $\mathrm{a}$ and $\mathrm{b}$ corresponding to its intercept and slope respectively [26].

A plot $\mathrm{E}_{\mathrm{corr}} \mathrm{vs} \log \mathrm{C}_{\mathrm{HCl}}$ is shown in figure (3) where a linear relationship is obtained which follows the equation [27].

$\mathrm{E}_{\mathrm{corr}}=\mathrm{a}-\mathrm{b} \log \mathrm{C}_{\mathrm{HCl}}$

Where $a$ and $b$ are constants.

Fig. (4) reveals that $\mathrm{I}_{\text {pass }}$ decrease with increase the $\mathrm{HCl}$ concentration due to the increase of thickness of passive layer $(\mathrm{CuCl})$ on copper surface. A linear relationship between concentration of $\mathrm{HCl}$ and $\mathrm{I}_{\text {pass }}$ is obtained in Fig.(4).

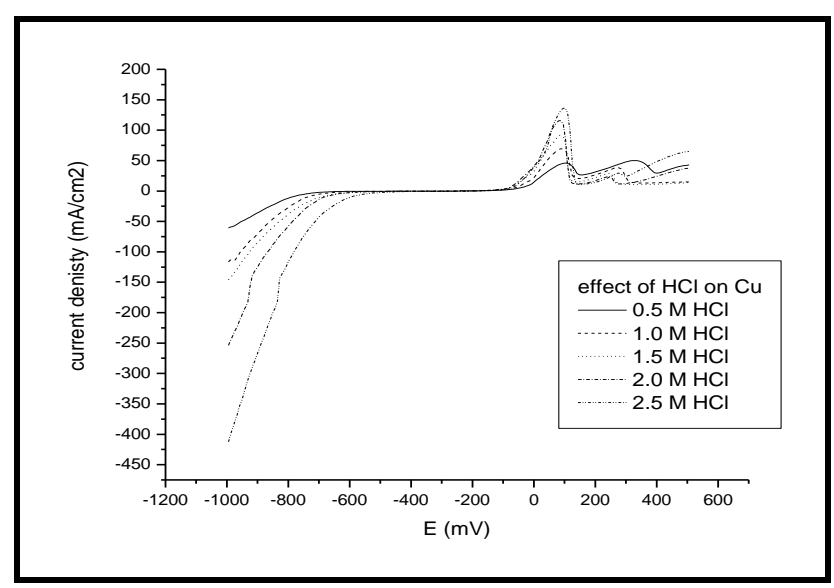

Fig.1 potentiodynamic polarization curves for Copper electrode in different concentrations of $\mathrm{HCl}$ with scan rate $10 \mathrm{mV} / \mathrm{S}$ at $25^{\circ} \mathrm{C}$ 


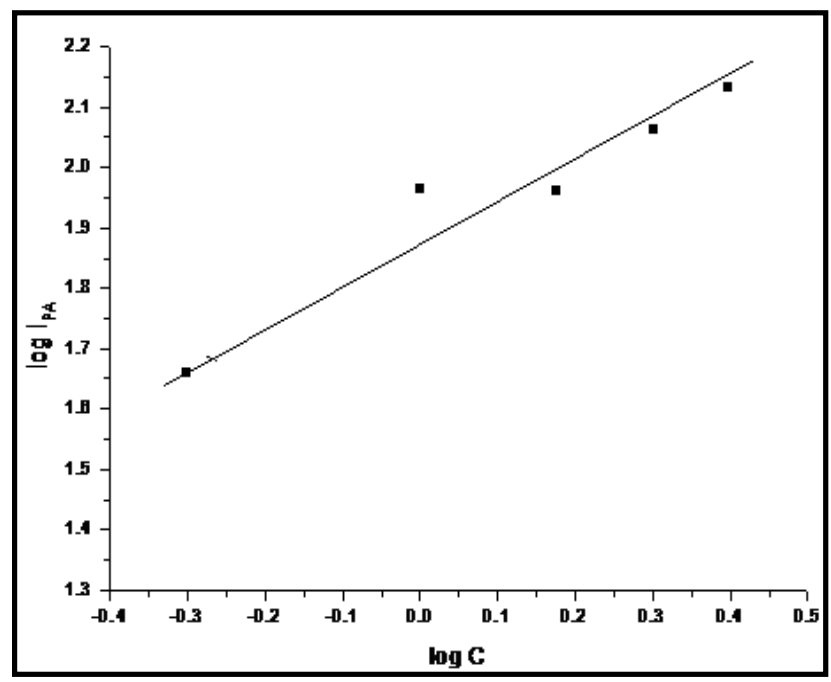

Fig. 2 Relationship between $\log C$ vs $\log \mathrm{I}_{\mathrm{PA} 1}$

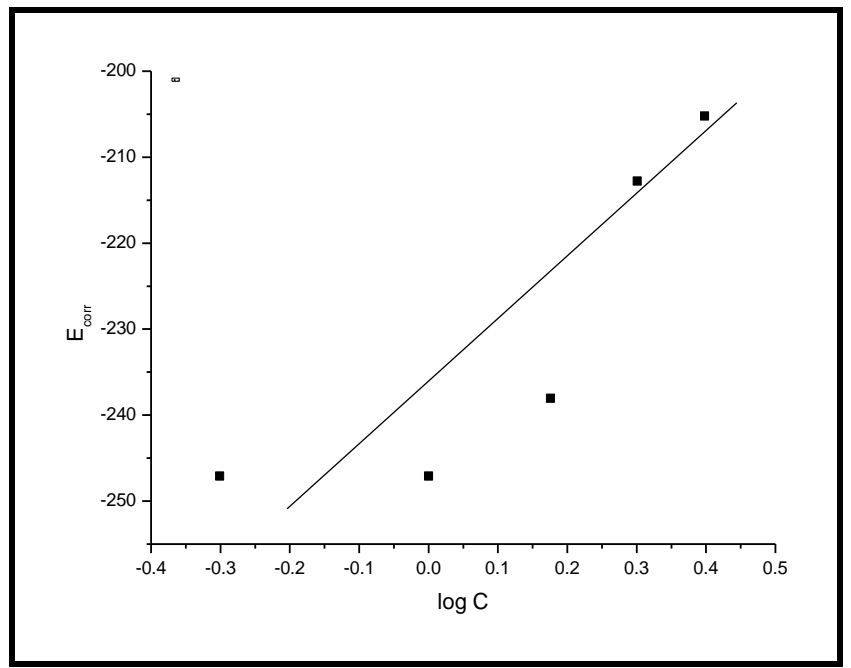

Fig. 3 Relationship between $\log \mathrm{C}$ of vs $\mathrm{E}_{\text {corr }}$

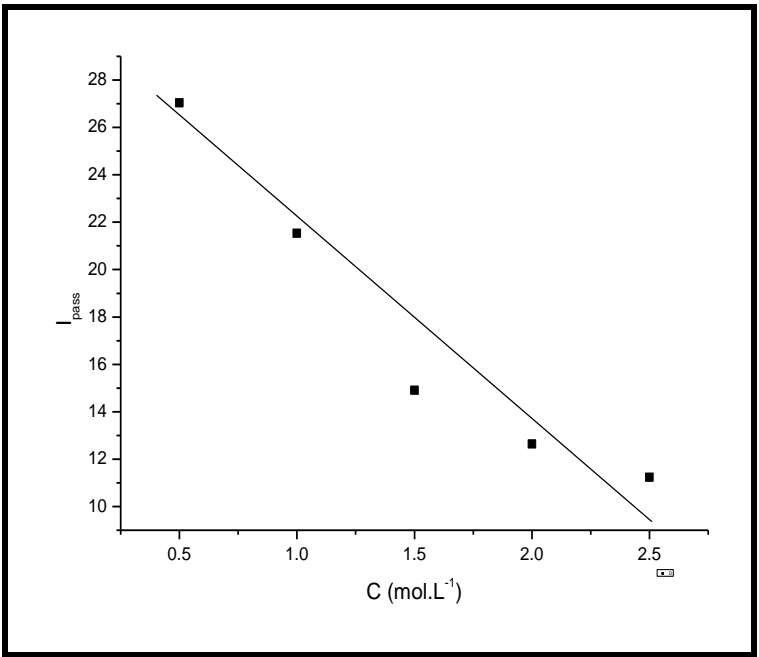

Fig. 4 Relationship between $I_{\text {pass }}$ and different concentrations of $\mathrm{HCl}$

\subsection{Effect of inorganic inhibitors on the corrosion characterization of $\mathrm{Cu}$ :}

Fig. (5) displays the influence of $\mathrm{MoO}_{4}{ }^{--}$on the potentiodynamic polarization curves of copper in $\mathrm{HCl}$. The $\mathrm{MoO}_{4}{ }^{--}$ion decreases the height of peak current densities of peak $\mathrm{A}_{1}$ and shift corresponding peak potential $\mathrm{E}_{\mathrm{PA} 1}$ to more positive potential. The primary inhibitive function 
of this anion is believed to be associated with their adsorption on the metal surface and retarding the entry of Copper ions into the solution at the anode [26].

The properties of molybdate solutions change with $\mathrm{pH}$ [29-30]. In alkaline solution, molybdate specie is present in the monomer form: $\mathrm{MoO}_{4}{ }^{2-}$. In neutral or acid solutions, molybdate specie polymerises to form a series of polymolybdates. The size of these polyanions increases with decrease of $\mathrm{pH}$. At about $\mathrm{pH} 6$, the first reaction is the formation of paramolybdate: $\mathrm{Mo}_{7} \mathrm{O}_{24}{ }^{6-}$. At lower $\mathrm{pH}$, the octamolybdate is formed: $\mathrm{Mo}_{8} \mathrm{O}_{24}{ }^{6-}$ Larger polyanions can be formed with further decrease of $\mathrm{pH}$.

The polymeric ion formation can be symbolised with the reaction [31]:

$\mathrm{n} \mathrm{MoO}_{4}{ }^{2-}+2 \mathrm{nH}^{+} \rightarrow \mathrm{H}_{2 \mathrm{n}}\left(\mathrm{MoO}_{4 \mathrm{n}}\right)$

Table (1) shows the values of corrosion current $\left(\mathrm{I}_{\text {corr }}\right)$ and the protection efficiencies $(\% \mathrm{P})$ of different concentrations of molybdate.

\begin{tabular}{|c|c|c|}
\hline $\mathrm{C}_{\mathrm{MoO4}{ }^{-}}{ }^{-}(\mathbf{m o l} / \mathrm{L})$ & $\mathbf{I}_{\text {corr }}\left(\mathbf{m A} / \mathbf{~ c m}^{2}\right) \times \mathbf{1 0}^{-1}$ & $\mathbf{P \%}$ \\
\hline 0.0 & 1.841 & - \\
\hline 0.002 & 0.927 & 49.65 \\
\hline 0.004 & 0.475 & 73.17 \\
\hline 0.006 & 0.450 & 75.56 \\
\hline 0.008 & 0.384 & 79.17 \\
\hline 0.01 & 0.496 & 73.04 \\
\hline
\end{tabular}

The relationship between $\mathrm{I}_{\mathrm{PA} 1}$ against $\mathrm{C}_{\mathrm{inh}}$ is given in Fig. (6) Whereby a straight line relation is noted. The inhibitory properties of this anion increase with their concentrations. So $\mathrm{MoO}_{4}{ }^{--}$ function as efficient inhibitor for active dissolution of copper in $\mathrm{HCl}$.

The effect of addition of different concentrations of $\mathrm{CrO}_{4}^{--}$as Potassium salt on the potentiodynamic response for Copper electrode in $1.0 \mathrm{M} \mathrm{HCl}$ solution was examined.

Fig. (7) represents voltammetric response for Copper under the influence of adding increasing concentrations of $\mathrm{CrO}_{4}^{--}$anion stimulates the active dissolution of Copper and increase the peak current densities $\mathrm{I}_{\mathrm{PA} 1}$. The stimulating influence of this anion is due to its oxidizing power. The decrease in cathodic polarization of a metal accelerates its active dissolution in an electrolyte containing a concentration of anodic inhibitors insufficient for inhibition [28]. Increase of effectiveness of cathodic process is accompanied by depassivation of the electrode, which leads to arise $\mathrm{I}_{\mathrm{PA} 1}$.

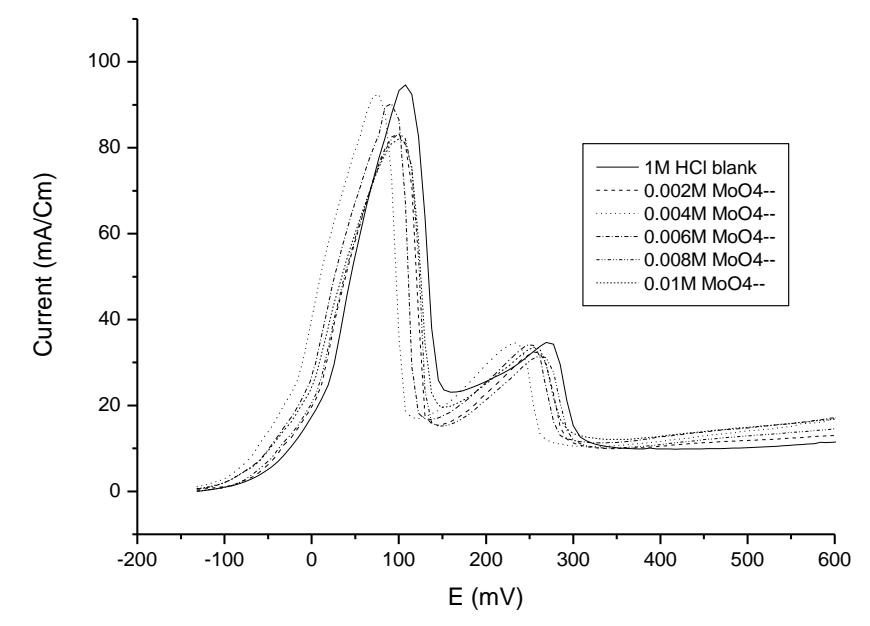

Fig. 5 potentiodynamic polarization curves for Copper electrode in $1.0 \mathrm{M} \mathrm{HCl}$ with different concentrations of $\mathrm{MoO}_{4}^{--}$with scan rate $10 \mathrm{mV} / \mathrm{S}$ at $25^{\circ} \mathrm{C}$ 


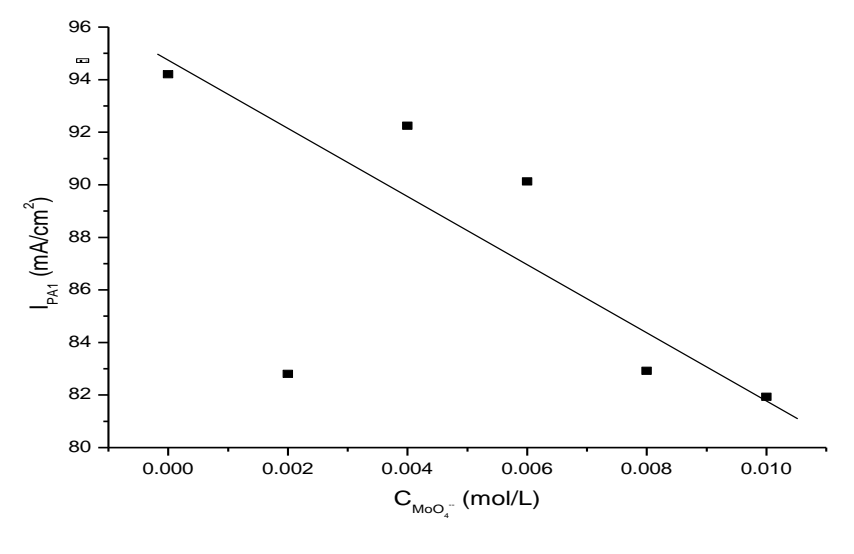

Fig. 6 Relationship between $\mathrm{C}_{\mathrm{MoO4}-\text {-vs I }} \mathrm{I}_{\mathrm{PA} 1}$

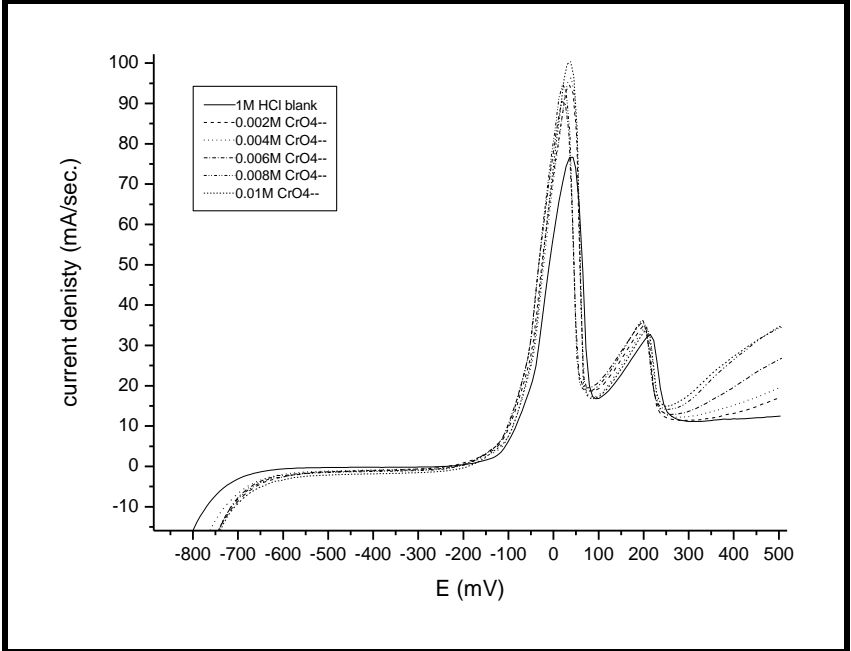

Fig.7 Potentiodynamic polarization curves for Copper electrode in $1.0 \mathrm{M} \mathrm{HCl}$ containing different concentrations of chromate with scan rate $10 \mathrm{mV} / \mathrm{S}$ at $25^{\circ} \mathrm{C}$

\section{The electrochemical impedance spectroscopy:}

Figs. (8-9) show the Nyquist plots for Copper in $1.0 \mathrm{M} \mathrm{HCl}$ solution in the absence and presence of different concentrations of $\mathrm{NaMoO}_{4}$ and $\mathrm{K}_{2} \mathrm{CrO}_{4}$ at $25^{\circ} \mathrm{C}$. The obtained Nyquist impedance diagrams in all cases does not show perfect semicircle, generally attributed to the frequency dispersion as a result of roughness and inhomogenates of the electrode surface[3234].

The diameter of the semicircle is associated with the polarization resistance and thus the corrosion rate. The larger the semicircle diameter, the lower the corrosion rate. Thus the highest corrosion rate is obtained for the uninhibited solution.

It is clearly seen from Figs. (8-9) that the diameter of the semicircle increases with $\mathrm{Na}_{2} \mathrm{MoO} 4$ concentration. On the other hand the diameter of the semicircle decreases in the presence of $\mathrm{K}_{2} \mathrm{CrO}_{4}$. These results indicate that the presence of $\mathrm{Na}_{2} \mathrm{MoO}_{4}$ has the inhibition effect on the corrosion of copper in $1.0 \mathrm{M} \mathrm{HCl}$ solution, while the addition of $\mathrm{K}_{2} \mathrm{CrO}_{4}$ leads to accelerate the corrosion of copper in $1.0 \mathrm{M} \mathrm{HCl}$ solution.

Figs. (8-9) show EIS diagrams with the provided equivalent circuit where $\mathrm{R}_{\mathrm{s}}$ respresents solution resistance, $\mathrm{R}_{\mathrm{ct}}$ charge transfer resistance, $\mathrm{C}_{\mathrm{dl}}$ the double layer capacitance for oxide film, CPE the constant phase element and $\mathrm{R}_{\text {oxide }}$ oxide film resistance.

The electrochemical impedance parameters derived from these investigations are mentioned in table (2).

From the impedance value obtained, the protection efficiency was calculated according to:

$\mathrm{P} \%=\left[\mathrm{R}_{\mathrm{ct}}-\mathrm{R}_{\mathrm{ct}(0)} / \mathrm{R}_{\mathrm{ct}}\right] \times 100$ 
Where $\mathrm{R}_{\mathrm{ct}}$ and $\mathrm{R}_{\mathrm{ct}(0)}$ are the charge transfer resistance with and without inhibitor, respectively. The values of protection efficiency $\mathrm{P} \%$ are listed in table (2).

It is apparent that in presence of $\mathrm{NaMoO}_{4}$ the value of $\mathrm{R}_{\mathrm{ct}}$ and $\mathrm{P} \%$ increases where as the value of $\mathrm{C}_{\mathrm{dl}}$ decreases. Further the increase in $\mathrm{NaMoO}_{4}$ concentration brings about an increase in the $\mathrm{P} \%$ and $\mathrm{R}_{\mathrm{ct}}$ values in presence of $\mathrm{NaMoO}_{4}$ is attributed to the formation of a protective film on the copper/ $\mathrm{HCl}$ interface.

The decrease in $\mathrm{C}_{\mathrm{dl}}$ values, which normally results in the dielectric constant and/ or an increase in the double layer thickness, can be attributed to the adsorption of inhibitors onto the metal/ electrolyte interface.

Protection efficiency is observed from table (2) and the optimum concentration for protection was $0.008 \mathrm{M}$ with an efficiency $79.17 \%$.

The results obtained from the polarization technique in acidic solution were in good agreement with those obtained from the electrochemical impedance spectroscopy (EIS) with a small variation.

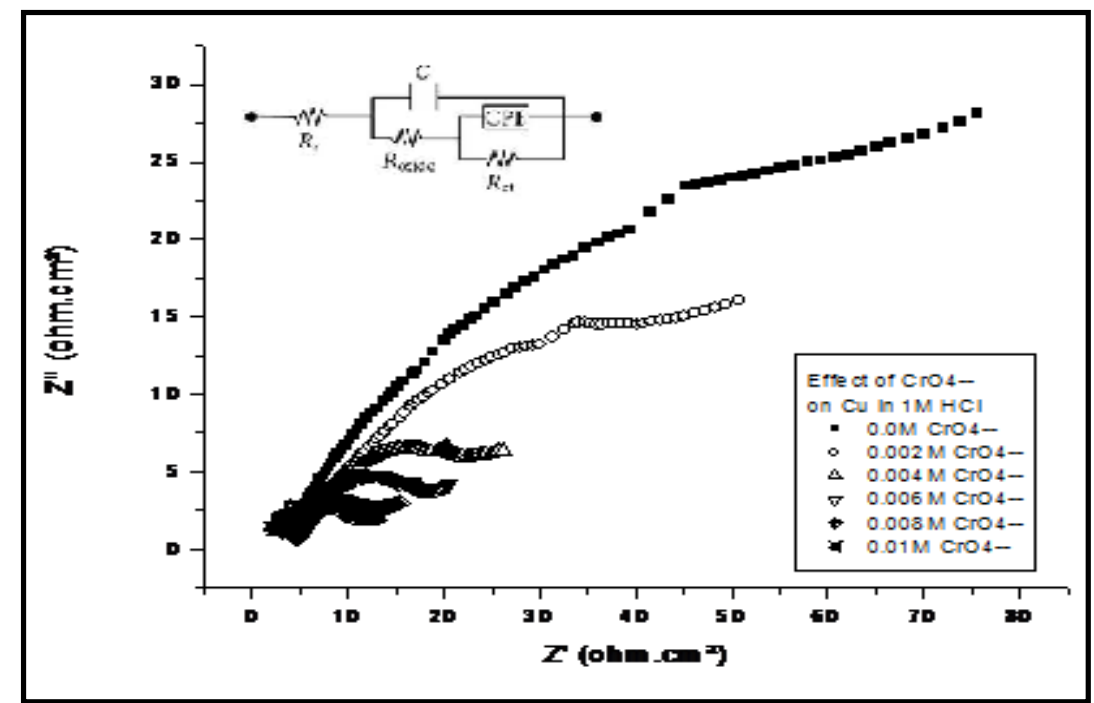

Fig 8. Nyquist plots for copper electrode in $1.0 \mathrm{M} \mathrm{HCl}$, without and with different concentration of $\mathrm{K}_{2} \mathrm{CrO}_{4}$ at $25^{\circ} \mathrm{C}$ Inset: the proposed equivalent circuit of the impedance results.

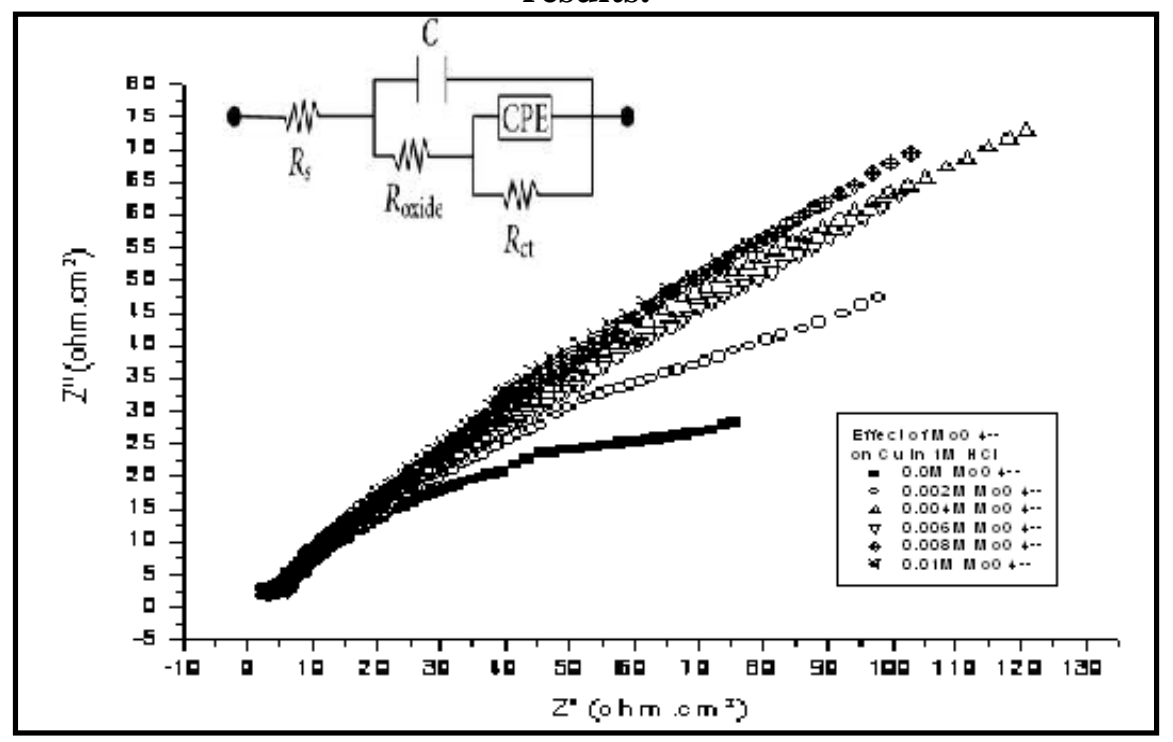

Fig 9. Nyquist plots of copper in $1.0 \mathrm{M} \mathrm{HCl}$, without and with different concentration of $\mathrm{Na}_{2} \mathrm{MoO}_{4}$ at $25^{\circ} \mathrm{C}$ Inset: the proposed equivalent circuit of the impedance results 
Table 2: The electrochemical Parameters and the corresponding protection efficiency of $\mathrm{Cu}$ in $1.0 \mathrm{M} \mathrm{HCl}$ in the absence and presence of different concentrations of $\mathrm{CrO}_{4}{ }^{--}$and $\mathrm{MoO}_{4}{ }^{--}$with scan rate $10 \mathrm{mV} / \mathrm{S}$ at $25^{\circ} \mathrm{C}$ (EIS)

\begin{tabular}{|c|c|c|c|}
\hline $\mathrm{K}_{2} \mathrm{CrO}_{4}$ conc. $(\mathrm{M})$ & $\mathbf{R}_{\mathrm{ct}}\left(\mathrm{Ohm} \cdot \mathrm{cm}^{2}\right) \times 10^{2}$ & \multicolumn{2}{|c|}{$C_{d l}\left(\mu \mathrm{F} / \mathrm{cm}^{2}\right) \times 10^{-3}$} \\
\hline 0.0 & 1.417 & \multicolumn{2}{|l|}{2.653} \\
\hline 0.002 & 0.946 & \multicolumn{2}{|l|}{3.793} \\
\hline 0.004 & 0.376 & \multicolumn{2}{|l|}{4.046} \\
\hline 0.006 & 0.293 & \multicolumn{2}{|l|}{3.761} \\
\hline 0.008 & 0.182 & \multicolumn{2}{|l|}{5.959} \\
\hline 0.01 & 0.158 & \multicolumn{2}{|l|}{4.673} \\
\hline $\mathrm{Na}_{2} \mathrm{MoO}_{4}$ conc. & $R_{\mathrm{ct}}\left(\mathrm{Ohm}_{.} \mathrm{cm}^{2}\right) \times 10^{2}$ & $\mathrm{C}_{\mathrm{dl}}\left(\mu \mathrm{F} / \mathrm{cm}^{2}\right) \times 10^{-}$ & $\mathbf{P}(\%)$ \\
\hline 0.0 & 1.417 & 2.653 & - \\
\hline 0.002 & 2.814 & 2.834 & 49.64 \\
\hline 0.004 & 5.493 & 1.759 & 74.20 \\
\hline 0.006 & 5.797 & 2.293 & 75.56 \\
\hline 0.008 & 6.803 & 1.877 & 79.17 \\
\hline 0.01 & 5.256 & 2.518 & 73.04 \\
\hline
\end{tabular}

\section{Conclusion}

The potentiodynamic polarization technique approved that the corrosion rate of copper increases by increasing the concentration of $\mathrm{HCl}(0.5 \mathrm{M}-2.5 \mathrm{M})$ with the appearance of 2 anodic peaks at $0.08 \mathrm{~V}$ and $0.26 \mathrm{~V}$.

The potentiodynamic polarization technique and EIS approved that different concentrations of $\mathrm{MoO}_{4}^{--}$inhibits the corrosion of copper in $1 \mathrm{M} \mathrm{HCl}$ with an optimum concentration $0.008 \mathrm{M}$ with a protection efficiency $79.17 \%$, while $\mathrm{CrO}_{4}{ }^{--}$accelerates the corrosion of copper in $1 \mathrm{M}$ $\mathrm{HCl}$ due to its oxidizing power.

\section{References}

[1] L. Núñez, E. Reguera, F. Corvo, E. González, C. Vazquez, Corros. Sci. 47 (2005), pp. 461-484.

[2] H.P. Hack, H.W. Pickering, J. Electrochem. Soc. 138 (1991), pp. 690-695.

[3]. W. Qafsaoui, G. Mankowski, P. Leterrible and F. Dabosi, Proc. Inf. Symp. on Control of Copper and CopperAlio s Oxidation, July 6-8, 1992, Rotten, France Revue de MetaNurgie, serie 6, (1992), pp. 63.

[4] P. E. Francis, W. K. Cheung and R. C. Pemberton, Proc. 11th Int. Corr. Gong., Florence, Italy, , Ed. AssociazioneItaliana di Metallurgia,( 2-6 April 1990) Vol. 5, pp. 363.

[5] S.A.M. Refaey, S.S. Abd El Rehim, Electrochim. Acta 42 (4) (1996), pp. 667.

[6] S.A.M. Refaey, Electrochim. Acta 41 (16) (1996), pp. 2549.

[7] S.A.M. Refaey, J. Appl. Electrochem. 26 (1996), pp. 503.

[8] S.A.M. Refaey, Appl. Surf. Sci. 157 (2000), pp. 199.

[9] S.S. Abd El-Rehim, S.A.M. Refaey, F. Taha, M.B. Saleh, R.A.Ahmed, J. Appl. Electrochem. 31 (2001), pp. 435.

[10] E.M. Sherif, R.M. Erasmus, J.D. Comins, J. Colloid Interface Sci. 311 (2007), pp. 144.

[11] E.M. Sherif, R.M. Erasmus, J.D. Comins, J. Colloid Interface Sci. 306 (2007) , pp.96.

[12] E.M. Sherif, S.-M. Park, J. Electrochim. Acta 51 (2006), pp. 6556.

[13] E.M. Sherif, S.-M. Park, J. Electrochim. Acta 51 (2006), pp. 4665. 
[14] M.M. Critchley, N.J. Cromar, N.C. McClure, H.J. Fallowfield, The influence of composition of drinking water on cuprosolvency by biofilm bacteria, J. Appl. Microbiol. 94 (2003), pp. 501-507.

[15] M. Edwards, L. Hidmi, D. Gladwell, Phosphate inhibition of soluble copper corrosion by-product release, Corros. Sci. 44 (2002), pp. 1057-1071.

[16] S.O. Pehkonen, A. Palit, X. Zhang, Effect of specific water quality parameters on copper corrosion, Corrosion 58 (2002), pp.156-165.

[17] Y. Zhe, S.O. Pehkonen, Copper corrosion kinetics and mechanisms in the presence of chlorine and orthophosphate, Water Sci. Technol. 49 (2004), pp. 73-81.

[18] S. Li, L. Ni, C. Sun, L. Wang, Influence of organic matter on orthophosphate corrosion inhibition for copper pipe in soft water, Corros. Sci. 46 (2004), pp. 137- 145.

[19] N. Soussi, E. Triki, A chemiometric approach for phosphate inhibition of copper corrosion in aqueous media, J. Mater. Sci. 42 (2007), pp. 3259-3265.

[20] N. Souissi, E. Triki, Modelling of phosphate inhibition of copper corrosion in aqueous chloride and sulphate media, Corros. Sci. 50 (2008), pp. 231-241.

[21] K. Goh, T. Lim, P. Chui, Evaluation of the effect of dosage, $\mathrm{pH}$ and contact time on high-dose phosphate inhibition for copper corrosion control using response surface methodology (RSM), Corros. Sci. (2008), pp. 918-927.

[22] M. Drogowska, L. Brossard, H. Menard, Comparative study of copper behavior in bicarbonate and phosphate aqueous solutions and effect of chloride ions, J. Appl. Electrochem. 24 (1994), pp. 344-349.

[23] M. Scendo, Corros. Sci. 47 (2005) 1738-1749.

[24] M. Scendo, Corros. Sci. 47 (2005) 2778-2791.

[25] E.M. Sherif, S.M. Park, Corros. Sci. 48 (2006) 4065-4079.

[26] P. Delahay, "New Instrumental Methods in Electrochemistry", Wiley, New York (1954), pp.124.

[27] S. S. Abd El Rehim, A. M. Abd El Halim and E. E. Foad El Sherbini, Surface Technology, 18 (1983), pp. 313.

[28] E. E. Foad El-sherbini, Corrosion Science, vol. 48 (2006), pp. 193.

[29] G.D. Wilcox, D.R. Gabe, M.E. Warnick, Corr. Rev. 6 (1986) 327.

[30] M. Pourbaix, Atlas d'e'quilibre e'lectrochimique a' 25 8C, Gauthier- Villars (Ed.), 1963.

[31] W.S. Li, L.P. Tian, Q.M. Huang, J. Power Sources 104 (2002) 281.

[32] J. J. Shim , J. G. Kim, Copper corrosion in potable water distribution systems: influence of copper products on the corrosion behavior, Materials Letters, 58, 14 (2004) , pp. 2002.

[33] M. Xu , H. D. Dewald, Impedance studies of copper foil and graphite-coated copper foil electrodes in lithium-ion battery electrolyte, Electrochimica Acta, 50, 27(2005), pp. 5473

[34] Y. Feng, W. K. Teo, K. S. Siow, K. L. Tan, A. K. Hsieh, The corrosion behaviour of copper in neutral tap water. Part I: corrosion mechanisms, Corrosion Science, 38, 3 (1996) , pp. 369. 